\title{
DZART: INVESTIGAÇÃO ACERCA DAS POSSIBILIDADES METODOLÓGICAS DO DESIGN E SEU USO EM PROCESSOS DE ARTESANIA
}

\author{
Rosangela Canonica \\ Instituto Federal de Santa Catarina - IFSC ${ }^{1}$ \\ rcanoni@yahoo.com.br \\ Rita Petrykowski Peixe \\ Instituto Federal de Santa Catarina - IFSC \\ ritapeixe@hotmail.com \\ llana Thaís de Andrade \\ Instituto Federal de Santa Catarina - IFSC \\ ilanathaisdeandrade@gmail.com \\ Rita da Costa \\ Instituto Federal de Santa Catarina - IFSC \\ ritadacosta1@hotmail.com
}

Resumo: A investigação descrita no presente artigo tem como ponto de partida as inúmeras demandas da área artesanal, principalmente no que se refere a processos cujo resultado seja um produto de qualidade reconhecida e que traduza os valores e características da sua região de origem. Proposto com $\mathrm{o}$ objetivo de investigar possibilidades metodológicas do design e seu uso em processos de artesania, o projeto de pesquisa teve como resultado a abordagem 3D's do Dzart, ancorada em experiências extensionistas importantes junto a artesãos, aliadas a estudos referenciando metodologias projetuais da área do design. As produções resultantes da utilização dessa metodologia pelos artesãos têm representado importantes contribuições no contexto do design social.

Palavras-chave: design, artesania, metodologia projetual

Asbtract: The research described in this article takes as its starting point the numerous demands of the craft area, mainly with regard to processes whose result is recognized as a quality product and reflecting the values and characteristics of its region of origin. Proposed in order to investigate methodological possibilities of design and its use in craftsmanship processes, the research project has resulted in 3D's Dzart approach, anchored in important extension experiences with the artisans, together with research referencing projective methodologies of design área.The

\footnotetext{
${ }^{1}$ Grupo de pesquisa DZART/ Instituto Federal de Santa Catarina - IFSC
} 
resulting productions using this methodology by artisans have represented important content of studies in the field of social design .

Keywords: design, craftsmanship, projective methodologies

\section{INTRODUÇÃO}

O produto artesanal sempre acompanhou o ser humano, resultado da sua curiosidade e capacidade inventiva voltada para a solução dos problemas que lhe impunham ao longo da vida. Com o advento da indústria, as atividades manuais foram substituídas pelos processos de mecanização e, a despeito das mudanças impostas pela industrialização, a artesania seguiu paralelamente como atividade alternativa. 0 design nasceu com o propósito de unir a produção industrial e os processos artísticoartesanais, resultando em produtos que buscavam satisfazer as necessidades dos usuários.

Para conceberem os produtos, os designers têm lançado mão de metodologias projetuais, as quais objetivam auxiliá-los em todas as etapas do seu processo, desde a criação do produto até a sua realização. Atualmente, com a expansão e recuperação dos processos artesanais - que ocuparam, por muito tempo, uma posição marginal no contexto da sociedade de consumo - e a consolidação de grupos de artesãos nas mais diferentes regiões do país, novos olhares são lançados para a produção artesanal. Com isso, motivações e preocupações têm sido pauta de discussões, destacando-se a relação entre design e artesania, principalmente no que diz respeito à qualificação dos processos artesanais e os procedimentos pelos quais o artesão desenvolve seu produto, escopo da investigação intitulada Dzart. A despeito dos inúmeros relatos de experiência e discussões sobre o assunto, estudos dessa natureza se fazem pertinentes, nos quais as abordagens possibilitem novos aportes visando à sua compreensão. Na proposta do presente artigo, apresenta-se parte dessa pesquisa, que procura explicitar aspectos dos processos artesanais, buscando compreender, de forma mais consistente, como as possibilidades metodológicas do design podem ser utilizadas nos processos de artesania.

\section{DZART: BREVE CONTEXTUALIZAÇÃO DO PROJETO DE PESQUISA}

O projeto de pesquisa Dzart resulta da premissa de tornar os conhecimentos em design acessíveis àqueles que, de modo empírico, produzem objetos artesanais nos mais diferentes contextos e variabilidade de técnicas. Seus estudos, vinculados à graduação, pós-graduação e extensão universitária, concentram investigações voltadas ao desenvolvimento de produtos de base artesanal atrelada à demanda de necessidades apontadas por artesãos de Joinville e região norte de Santa Catarina. Em seu âmbito, aproxima universidade e comunidade em ações de pesquisa-ação a fim de discutir aspectos culturais, metodológicos e estratégicos relacionados ao desenvolvimento de produtos.

O percurso da pesquisa delineia e mapeia inúmeras demandas que resultamem um projeto que investiga de que forma as possibilidades metodológicas do design podem ser utilizadas/adequadas aos processos de artesania, tendo como objetivo o desenvolvimento de referenciais que orientem os artesãos acerca dessas questões. Ao 
longo do percurso, as aproximações empreendidas buscaram investigar e levantar bibliografias que pudessem ancorar e dar suporte a essa temática e suas relações com o design social. Também foi verificado, junto aos gestores dos empreendimentos artesanais de Joinville e região, aspectos dos seus modos de atuação, considerando quais metodologias poderiam ser mais adequadas à sua realidade, a partir de suas experiências e processos de trabalho, visando encaminhamentos metodológicos. Alguns parâmetros possibilitaram sistematizar, de acordo com a adequabilidade, uma metodologia própria, utilizada experimentalmente em empreendimentos artesanais por meio das relações de ensino-aprendizagem.

É importante ressaltar que para o desenvolvimento da proposta de pesquisa (metodologia direcionada ao artífice) foram necessários quatro anos preliminares de observação, onde as performances práticas de designers junto a comunidades locais buscaram o empoderamento criativo do artesão de modo a desenvolver abordagens que respeitassem o propósito da colaboração, da valorização e da multiplicidade de saberes.

\section{PRINCIPAIS INVESTIGAÇÕES REALIZADAS}

As atividades investigativas do projeto de pesquisa Dzart fundamentam sua performance em oito principais ações, as quais consideram os seguintes objetivos específicos: (1) Explicitar as relações entre o design e os processos de artesania na atualidade; (2) Identificar as metodologias projetuais de design mais relevantes no contexto nacional e internacional; (3) Examinar as atuais relações entre design e artesanato e alguns dos seus resultados; (4) Questionar, junto a gestores da área artesanal, os encaminhamentos metodológicos já utilizados/propostos em atividades de consultoria; (5) Realizar um levantamento dos empreendimentos artesanais em Joinville e região e seus processos de trabalho; (6) Verificar, junto aos empreendimentos artesanais de Joinville e região, as metodologias utilizadas nos seus processos produtivos; (7) Sistematizar procedimentos metodológicos, visando sua utilização - de acordo com a adequabilidade - em empreendimentos artesanais; (8) Avaliar os resultados da experiência junto a um empreendimento artesanal piloto.

Os estudos realizados abarcam um percurso desenvolvido entre os anos de 2013 a 2016, organizados em quatro distintas fases, de modo que a periodicidade e objetivos propostos relacionam-se da seguinte maneira (Figura 1):

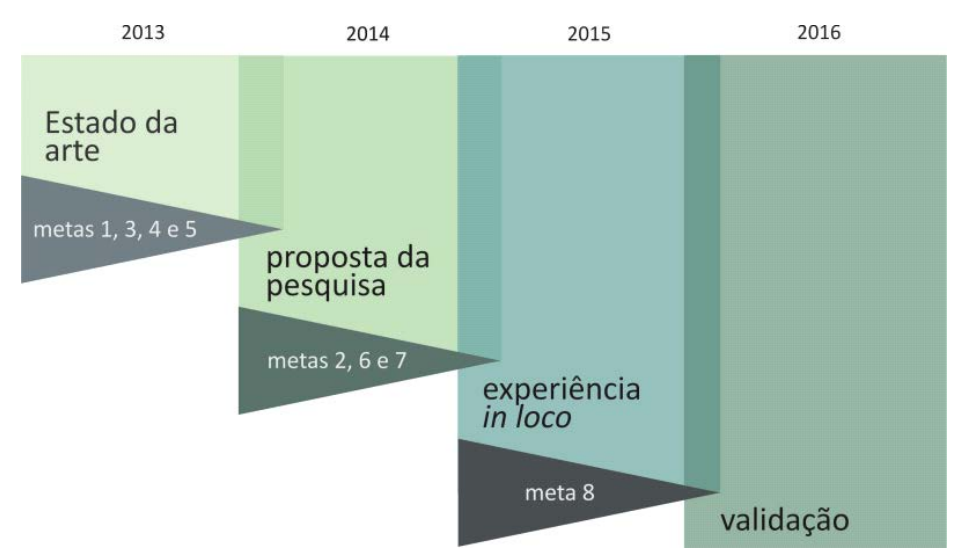

Figura 1 - Fases de pesquisas do projeto Dzart

Fonte: Elaborado pelos autores, com base na pesquisa realizada 
Salienta-se que as primeiras fases, compreendidas como Estado da Arte e Proposta da Pesquisa, correspondentes aos anos de 2013 e 2014 respectivamente, fundamentam os aspectos teóricos que norteiam e discutem possibilidades metodológicas do design para uso específico em processos da produção artesanal. Em síntese, foi realizado o estudo bibliográfico das relações entre artesanato e design; a verificação das metodologias para criação de produtos, em especial, as metodologias participativas; o estudo de casos de ações de design em prol da qualificação ou melhoria das condições dos processos de artesania; e, por fim, o levantamento dos processos de trabalho utilizados por artesãos da cidade de Joinville e região. A execução desses estudos fundamentou a construção de uma metodologia plausível à utilização pelos artífices.

A Figura 2 expõe as principais investigações relacionadas aos objetivos (3), (5) e (6), que demonstram aspectos importantes da pesquisa.

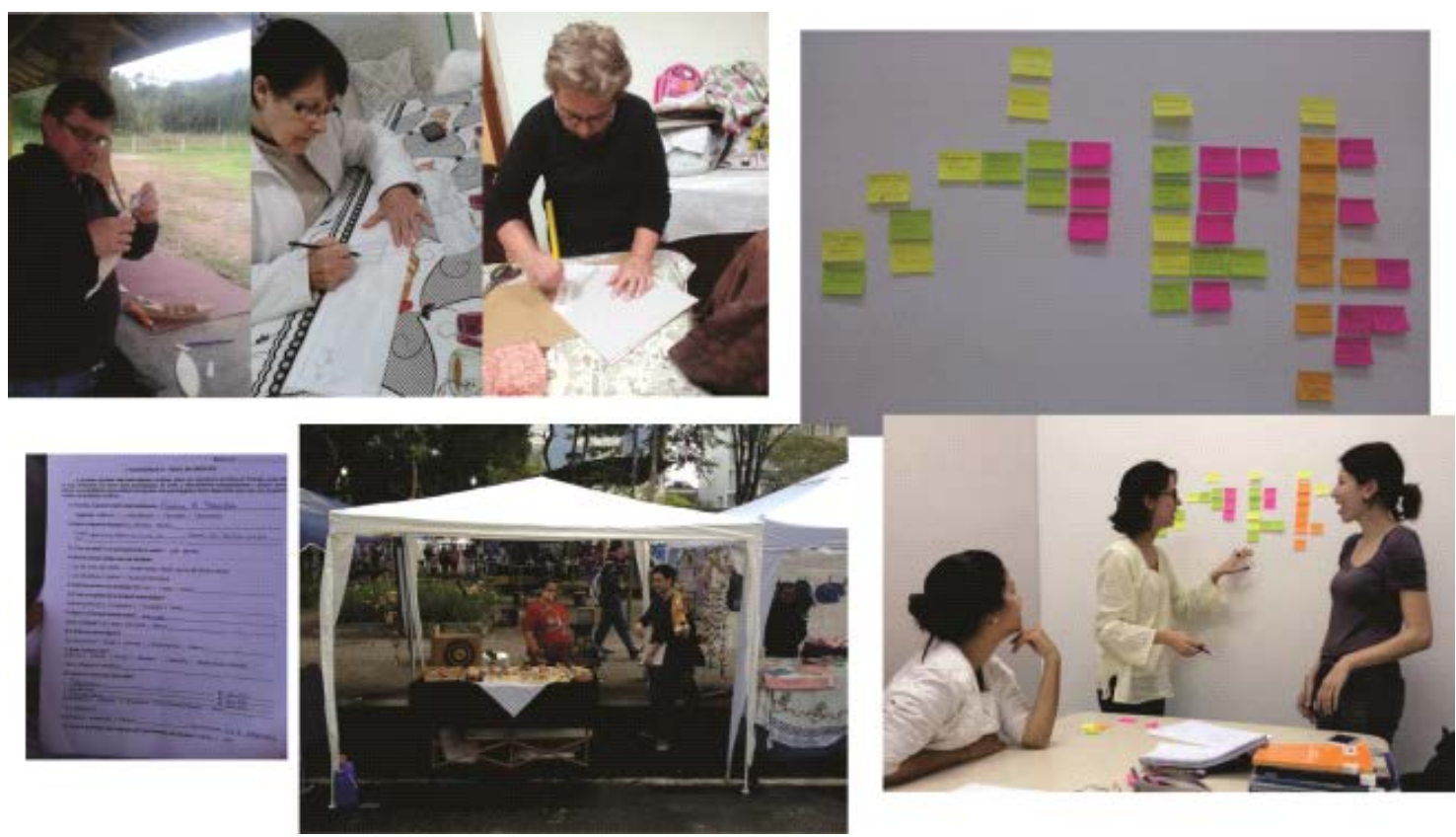

Figura 2 - Pesquisas de campo e painel visual (análise e síntese de metodologias projetuais) Fonte: Elaborado pelos autores, com base na pesquisa realizada

Contudo, as fases Experiência in loco e Validação, correlativas aos anos de 2015 e 2016, testam e ratificam o resultado da pesquisa junto a amostragens de artesãos (Figura 3).

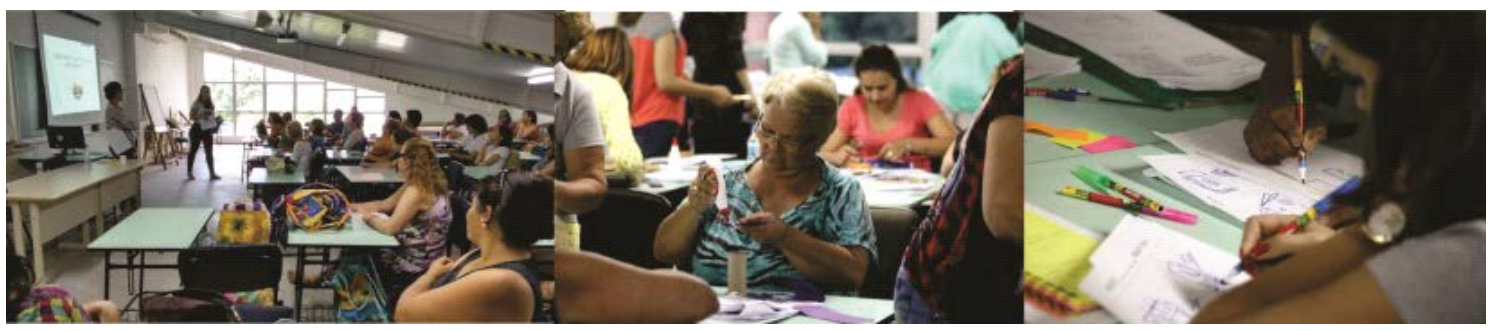

Figura 3 - Fase de testagem da metodologia criada

Fonte: Elaborado pelos autores, com base na pesquisa realizada 
Após seu processo de desenvolvimento e avaliações iniciais, ocorridas em 2015 (onde 50 artesãos fizeram parte do estudo de caso) a proposta metodológica passa a ser reaplicada a uma segunda amostragem (50 artesãos) no presente ano de 2016, de modo a receber adaptações e novos encaminhamentos, conforme sua aplicação, que possibilitem sua estabilização como um pensamento lógico e processual, tanto no auxílio ao artífice, em sua realidade de trabalho, como para que o designer social possa tecer relações de ensino-aprendizagem nesse contexto.

\subsection{Processo de desenvolvimento metodológico a partir do design}

Pensar em um produto é refletir sobre as escolhas processuais para desenvolvê-lo. A fim de buscar respostas adequadas à realidade do artífice, auxiliando seu fazer artesanal, diferentes metodologias consolidadas em áreas de criação, desenvolvimento e produção de produtos/serviços foram analisadas. Em especial, as que evidenciam processos participativos, por serem premissas do Dzart em suas relações de ensino-aprendizagem.

Baxter, Löbach, Design Thinking, Design Social, Design for Change, Design Centrado no Usuário, ancoram os referenciais metodológicos selecionados como parâmetros da pesquisa. Dentre as contribuições existentes, o Quadro 1 compara e identifica fases e aspectos relevantes a cada contexto.

\begin{tabular}{|c|c|c|c|}
\hline $\begin{array}{l}\text { REFERENCIAIS } \\
\text { METODOLÓGICOS }\end{array}$ & $\begin{array}{l}\text { № DE } \\
\text { FASES }\end{array}$ & FASES & $\begin{array}{l}\text { PONTOS CONSIDERADOS } \\
\text { RELEVANTES }\end{array}$ \\
\hline $\begin{array}{l}\text { Funil de decisões de } \\
\text { Baxter }\end{array}$ & 6 & $\begin{array}{l}\text { - Estratégia de negócio } \\
\text { - Melhor oportunidade de negócio } \\
\text { - Melhor oportunidade de produto } \\
\text { - Melhor conceito } \\
\text { - Melhor configuração } \\
\text { - Protótipo }\end{array}$ & $\begin{array}{l}\text { - Reflexão } \\
\text { - Tomada de decisão } \\
\text { - Esgotamento de } \\
\text { possibilidades. }\end{array}$ \\
\hline $\begin{array}{l}\text { Modelo } \\
\text { metodológico de } \\
\text { Lobach }\end{array}$ & 4 & $\begin{array}{l}\text { - Análise do Problema; } \\
\text { - Geração das Alternativas; } \\
\text { - Avaliação das Alternativas; } \\
\text { - Realização da solução }\end{array}$ & $\begin{array}{l}\text { - Foco na resolução de um } \\
\text { problema. }\end{array}$ \\
\hline $\begin{array}{l}\text { Design Thinking } \\
\text { para Educadores }\end{array}$ & 5 & $\begin{array}{l}\text { - Descoberta; } \\
\text { - Interpretação; } \\
\text { - Ideação; } \\
\text { - Experimentação; } \\
\text { - Evolução. }\end{array}$ & $\begin{array}{l}\text { - Auxilia a identificar a } \\
\text { oportunidade a partir de } \\
\text { problemas. } \\
\text { - Ferramentas úteis, } \\
\text { didáticas e bem } \\
\text { estruturadas. }\end{array}$ \\
\hline $\begin{array}{l}\text { Guia de Métodos } \\
\text { de Design Social } \\
\text { (KIMBELL e JULIER) }\end{array}$ & 4 & $\begin{array}{l}\text { - Explorar; } \\
\text { - Interpretar; } \\
\text { - Propor; } \\
\text { - Interagir }\end{array}$ & $\begin{array}{l}\text { - Metodologia Cíclica; } \\
\text { - Ferramentas úteis, } \\
\text { didáticas e bem } \\
\text { estruturadas. }\end{array}$ \\
\hline Design for Change & 4 & $\begin{array}{l}\text { - Sentir; } \\
\text { - Imaginar; } \\
\text { - Fazer; } \\
\text { - Compartilhar. }\end{array}$ & $\begin{array}{l}\text { - Linguagem simples e } \\
\text { didática. }\end{array}$ \\
\hline $\begin{array}{l}\text { Design Centrado no } \\
\text { Usuário }\end{array}$ & 3 & $\begin{array}{l}\text { - Ouvir; } \\
\text { - Criar; } \\
\text { - Entregar. }\end{array}$ & $\begin{array}{l}\text { - Imersão na vida do } \\
\text { usuário, ampla observação; } \\
\text { - Linguagem simples e } \\
\text { completa. }\end{array}$ \\
\hline
\end{tabular}

Quadro 1 - Comparação e Identificação de características relevantes entre metodologias. 
Em síntese, diante do quadro elaborado, é possível inferir que Baxter (2011), a partir da problematização, instiga a reflexão e afunilamento de possibilidades de solução, vislumbrando tomada de decisões mais assertivas. Adaptado a diferentes situações, permite realizar um esgotamento de possibilidades e escolher a alternativa que seja mais adequada e que elimine as chances de erro no projeto.

Em Löbach (2001) alcançamos a percepção de que todo projeto de desenvolvimento de produto parte de um problema, sendo a resolução desse problema a materialização de um produto carregado de características que incidem na solução. Para resolução desse problema é preciso ter claras as dimensões do problema e todos aspectos que se relacionam com ele.

Brown (2010) assegura que o design thinking constitui-se como uma abordagem à descoberta de fazer algo novo, eficiente e amplamente acessível. Assim,voltamos a atenção às pessoas que são protagonistas dos problemas em questão, observando como se relacionam, como são afetadas, e quais caminhos seguem para contornar o problema. A partir dessa observação, Gonsales (2014) em Design Thinking para Educadores, sinaliza para o uso de métodos que auxiliem na identificação de oportunidades, interagindo com as pessoas por meio de diferentes e acessíveis ferramentas práticas. Defende que as práticas participativas desenvolvem o senso de coletividade, colaboração e da exploração de novas possibilidades e desafios humanos, sobretudo, da experimentação da criatividade como processo de ensino e aprendizagem.

O Design Centrado no Usuário (PINHEIRO et al, s.n.t) considera uma profunda imersão no universo das pessoas, a partir do auxílio de ferramentas de simples utilização. Da mesma maneira, o Design for Change (s.n.t) simplifica esse processo em uma linguagem com apelo ao sensorial, estimulando as pessoas a sentirem o problema, se imaginarem no lugar das pessoas afetadas pelo problema e proporem soluções.

Por fim, Kimbell e Julier (2014), em seu guia de métodos do Design Social, propõem - por meio de suas ferramentas ilustradas - retomarem todo o processo ao chegar ao fim de sua execução, identificar quais novos problemas percebidos, após a solução do problema inicial, como um processo infinito de aperfeiçoamento e solução de problemas.

Independentemente dos contextos, todas as metodologias analisadas têm como essência, a resolução de problemas, diferenciando-se em suas diferentes abordagens. Apesar das sistematizações apresentadas, é oportuno afirmar que não existe uma fórmula ou receita exata ao processo, porém, há métodos flexíveis a cada contexto e situação, resultando em soluções adequadas, conforme fatores que incidem sobre os problemas.

No âmbito dos estudos realizados, não é possível nomear uma metodologia mais significante em relação a outra, visto que cada uma atende a alguns aspectos aos quaiso problema é proposto. Porém, é possível identificar em cada metodologia analisada, características relevantes que podem contribuir ao processo de criação artesanal e que melhor dialoguem com o artesão. Em especial, práticas visuais que permitem a atitude de experimentação, mantendo abertas novas possibilidades, novos direcionamentos e a disposição para novas soluções. 


\section{A METODOLOGIA (OU ABORDAGEM) 3D`S DO DZART}

Desenvolvida a partir da junção e adaptação das metodologias investigadas, levando em conta a realidade do artesão, a Metodologia (também denominada abordagem) 3D`s tem por objetivo fornecer uma sistematização que auxilie o artífice a refletir acerca da sua produção, estimulando-o a adotar um processo consciente de desenvolvimento de produtos. A intencionalidade de criação dessa abordagem aportada pelo Dzart é permitir que a metodologia se constitua como uma caixa de ferramentas: flexível e favorável, conforme as escolhas e aptidões de seu usuário.

Adotando uma aproximação que contempla diferentes situações de aplicação - tanto do designer como mediador quanto do artífice - a metodologia proposta parte de um problema genérico e estrutura-se em três fases que justificam seu nome: Descobrir, Decodificar e Desenvolver. A Figura 4 apresenta o modelo mental simplificado, expondo a sistematização referente a cada etapa.

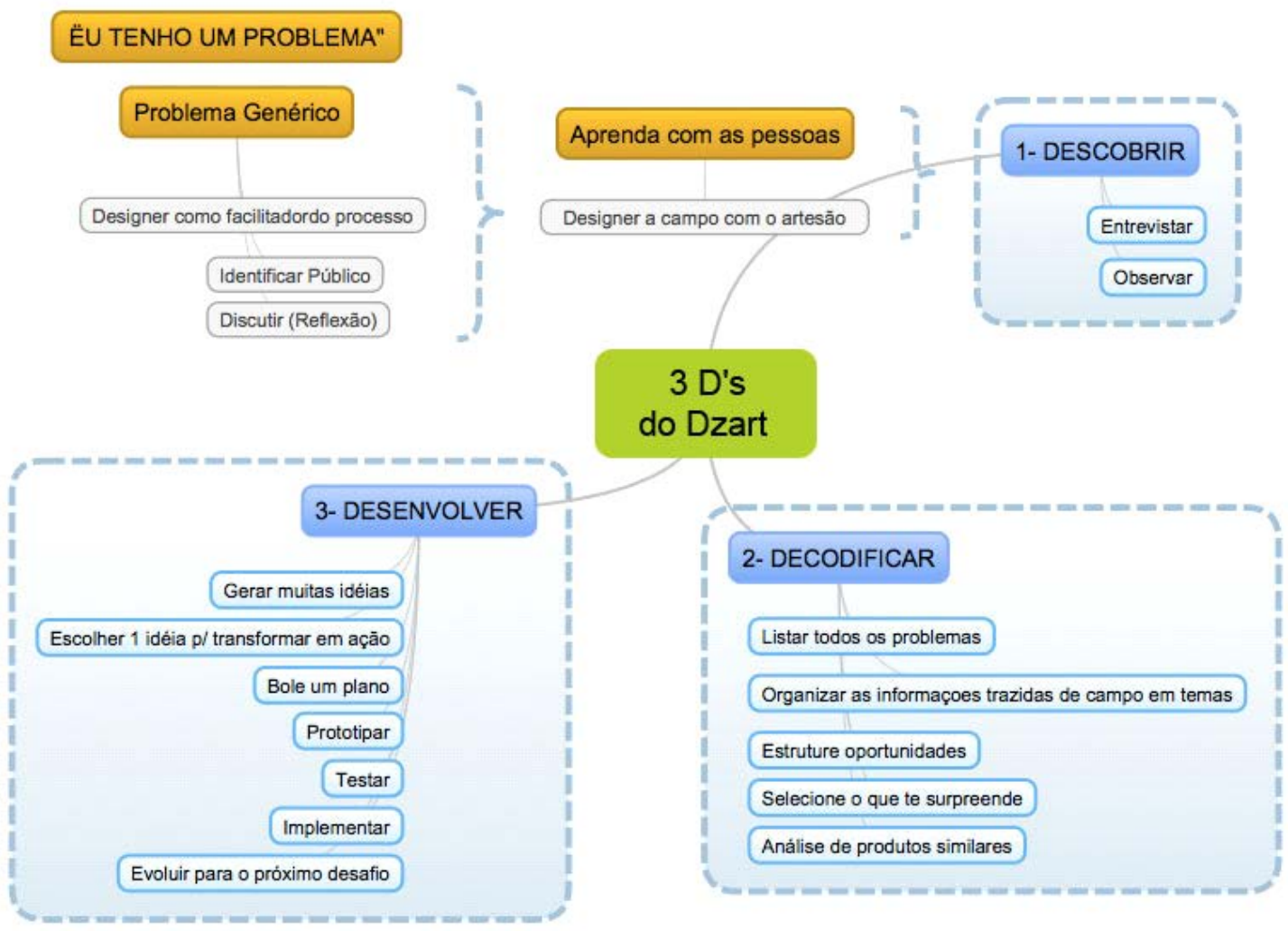

Figura 4 - Modelo do funcionamento da Metodologia 3D`s

Fonte: Elaborado pelos autores, com base na pesquisa realizada

Toda fase desdobra-se em métodos que se relacionam entre si para auxiliar no desenvolvimento do processo. A partir da identificação de um problema, considerado como desafio, inicia-se o processo de Descobrir o máximo de informações possíveis acerca do contexto. Essa fase de imersão permite Decodificar o foco projetual que permita ao artesão Desenvolver uma solução de design.

Para maior aprofundamento da metodologia, as etapas são descritas da seguinte maneira: 
I. Descobrir: nessa fase o artesão é estimulado a ouvir e aprender com as pessoas. É, portanto, o momento de imergir em uma determinada situação, se despindo de pré-conceitos para deixar-se inspirar com novas situações.

Nesse sentido, a partir de um problema genérico, o artífice é direcionado, por meio dos métodos de Observação e Entrevista, a se colocar no lugar de seu público. Ao aproximar-se de uma pesquisa empática - indo a campo para observar e entrevistar pessoas a respeito do problema em questão - o artesão busca perceber comportamentos e motivações das pessoas envolvidas na problemática, a fim de aprofundar conhecimentos e entender comportamentos. Isso o capacita a identificar necessidades físicas, cognitivas sociais e/ou culturais que lhe permitirão atender à sua demanda, com produtos e/ou serviços.

Nessa fase, encontram-se estruturados métodos de pesquisa atrelados ao suporte de ferramentas para registro e levantamento de dados, conforme descreve o Quadro 2.

\begin{tabular}{|c|c|c|}
\hline MÉTODOS & DESCRIÇÃO & FERRAMENTAS \\
\hline Observação & $\begin{array}{l}\text { - Momento de observar e registrar todas as questões que } \\
\text { incidem na ocorrência do problema, respondendo a } \\
\text { questões como: } \\
\text { - Qual o público se relaciona com o problema? } \\
\text { - Em quais ambientes costuma ocorrer o problema? De que } \\
\text { forma? } \\
\text { - Com que frequência? }\end{array}$ & $\begin{array}{l}\text { - Máquina Fotográfica, } \\
\text { - Diário de Campo, } \\
\text { - Caneta ou Lápis. }\end{array}$ \\
\hline Entrevista & $\begin{array}{l}\text { - Seleção de pessoas inseridas no contexto do problema - } \\
\text { que convivam frequentemente, ou que tenham se } \\
\text { destacado por alguma característica relevante - como } \\
\text { amostragem de pesquisa para realização de perguntas } \\
\text { direcionadas. }\end{array}$ & - Questionário \\
\hline
\end{tabular}

Quadro 2 - Métodos e ferramentas da fase Descobrir.

Fonte: Elaborado pelos autores, com base na pesquisa realizada

A realização dessa fase é fundamental para um melhor resultado de projeto, pois fundamenta todas as ações e tomadas de decisões futuras. Assim sendo, somente depois de realizado um cuidadoso levantamento de dados, é que o artesão está apto a seguir para a fase seguinte, onde irá decodificar as informações recolhidas, interpretando-as e atribuindo significados.

II. Decodificar: Essa é uma fase abstrata, em que o artesão realizará um processo de interpretação e síntese de toda a informação coletada, a fim de decodificar os problemas e necessidades registrados em um desafio potencial, uma oportunidade de inovação.

Nessa etapa os métodos concentram-se em conduzir o artesão a perceber os aprendizados obtidos na fase inicial. Por meio de ferramentas auxiliares, conforme disposto no Quadro 3, o artesão irá organizar os dados coletados classificando-os por temas, filtrando as informações relevantes e atribuindo-Ihes significados. 


\begin{tabular}{|c|c|c|}
\hline MÉTODOS & DESCRIÇÃO & FERRAMENTAS \\
\hline $\begin{array}{l}\text { Listar todos os } \\
\text { problemas }\end{array}$ & $\begin{array}{l}\text { A partir dos registros gerados na observação e das } \\
\text { informações resultantes das entrevistas, há a síntese de } \\
\text { problemas e necessidades em palavras-chave. } \\
\text { Por meio de um esgotamento de palavras, o artesão } \\
\text { deve ser orientado a listar o máximo de } \\
\text { problemas/necessidades. }\end{array}$ & $\begin{array}{l}\text { - Painel de } \\
\text { Problemas } \\
\text { (Palavras chave) }\end{array}$ \\
\hline $\begin{array}{l}\text { Organizar as } \\
\text { informações } \\
\text { trazidas de campo } \\
\text { em temas }\end{array}$ & $\begin{array}{l}\text { De posse do Painel de Problemas, o artesão é conduzido } \\
\text { a significar as palavras-chave descritas, organizando-as } \\
\text { por conjunto de temas. Cada tema, portanto, deve } \\
\text { coexistir junto a palavras-chave que representem sua } \\
\text { essência. }\end{array}$ & - Painel de Temas \\
\hline $\begin{array}{l}\text { Estruturar } \\
\text { Oportunidades }\end{array}$ & $\begin{array}{l}\text { A partir da organização temática das palavras chave } \\
\text { (Painel de Temas), o artesão irá filtrar o que é relevante } \\
\text { ao refinamento do seu desafio realizando um processo } \\
\text { de reflexão e seleção de alternativas relevantes. Em cada } \\
\text { tema, optará por suprimir palavras-chave. Depois, se } \\
\text { julgar necessário, eliminará temas, de modo que lhe } \\
\text { reste, em última instância, desafios concretos. }\end{array}$ & $\begin{array}{l}\text { - Funil de } \\
\text { oportunidades. }\end{array}$ \\
\hline $\begin{array}{l}\text { Selecionar o que } \\
\text { surpreende }\end{array}$ & $\begin{array}{l}\text { Alcançando o mínimo de palavras-chave, o artesão } \\
\text { conseguirá vislumbrar com maior facilidade problemas } \\
\text { que apresentam maior relevância de solução projetual. } \\
\text { Na busca por uma síntese, selecionará palavras-chave } \\
\text { que possuem maior inspiração, que o surpreendam por } \\
\text { alguma característica, que estimulem seu anseio de } \\
\text { resolução. }\end{array}$ & $\begin{array}{l}\text { - Definição de } \\
\text { Problema(s) } \\
\text { específico(s) - Foco } \\
\text { projetual. }\end{array}$ \\
\hline $\begin{array}{l}\text { Analisar Produtos } \\
\text { similares }\end{array}$ & $\begin{array}{l}\text { Com o Foco Projetual definido, há a busca por } \\
\text { referenciais de produtos que contemplem ou que } \\
\text { possuam características relacionadas à problematização. } \\
\text { O artesão é orientado a construir um painel contendo } \\
\text { imagens de produtos similares, buscando por diferentes } \\
\text { soluções já criadas, contextos semelhantes, etc. }\end{array}$ & $\begin{array}{l}\text { - Painel de } \\
\text { referenciais de } \\
\text { produtos disponíveis }\end{array}$ \\
\hline
\end{tabular}

Quadro 3 - Métodos e ferramentas da fase Decodificar.

Fonte: Elaborado pelos autores, com base na pesquisa realizada

O cumprimento desse processo ajudará o artesão a encontrar um caminho seguro para que possa seguir, como também lapidar seu desafio em um foco projetual fundamentado em análises de situações reais e inspiradas por pessoas. Esse foco projetual, ainda que abstrato, permitirá a realização de uma solução plausível, da qual se encarrega a próxima fase.

III. Desenvolver: A partir das definições das diretrizes de projeto, o artesão inicia a fase de desenvolvimento de um produto, atendendo aspectos técnicos relacionados à execução da ideia, buscando, sobretudo, atender seu público.

Nessa fase, prioriza-se o brainstorming, onde o artesão é estimulado a pensar de maneira ampla, sem inibições, expandindo suas perspectivas, em diferentes ideias, que podem parecer ousadas ou impraticáveis, mas que permitem alcançar resultados autorais.

Para viabilizar a ideação, o Quadro 4 expõe o uso de determinadas ferramentas. 


\begin{tabular}{|c|c|c|}
\hline MÉTODOS & DESCRIÇÃO & FERRAMENTAS \\
\hline $\begin{array}{l}\text { Gerar muitas } \\
\text { ideias }\end{array}$ & $\begin{array}{l}\text { Por meio de um brainstorming o artesão é estimulado a } \\
\text { listar muitas ideias. A proposta é gerar livres } \\
\text { possibilidades de solução, alcançando o maior número } \\
\text { de alternativas. }\end{array}$ & - Brainstorming \\
\hline $\begin{array}{l}\text { Escolher uma } \\
\text { ideia para } \\
\text { transformar } \\
\text { em ação }\end{array}$ & $\begin{array}{l}\text { A partir das alternativas geradas, o artesão opta pela } \\
\text { escolha da alternativa que melhor atenda às } \\
\text { especificações do seu projeto. }\end{array}$ & - Análise \\
\hline $\begin{array}{l}\text { "Bolar" um } \\
\text { plano }\end{array}$ & $\begin{array}{l}\text { Com a ideia selecionada, o artesão será instigado a } \\
\text { planejar a execução do produto, refletindo as questões: } \\
\text { O que? Por quê? Quem? Onde? Quando? Como? } \\
\text { Quanto? }\end{array}$ & - Planejamento 5W3H \\
\hline Prototipar & $\begin{array}{l}\text { Tendo como recurso o uso de materiais alternativos } \\
\text { (recicláveis) o artesão verifica o impacto do seu produto } \\
\text { ao prototipar sua ideia. }\end{array}$ & - Maquete \\
\hline Testar & $\begin{array}{l}\text { Com o protótipo feito, é hora de o artesão confirmar } \\
\text { com possíveis consumidores se o seu projeto atende ao } \\
\text { desafio proposto. Ouvir feedback, enriquece o } \\
\text { desenvolvimento da solução, expande sua aplicação a } \\
\text { possibilidades não pensadas, permitindo um resultado } \\
\text { final mais assertivo. }\end{array}$ & $\begin{array}{l}\text { - Ouvir feedback } \\
\text { - Pesquisa com Grupo } \\
\text { focal }\end{array}$ \\
\hline Implementar & Lançamento do produto final. & \\
\hline $\begin{array}{l}\text { Evoluir para o } \\
\text { próximo } \\
\text { desafio }\end{array}$ & $\begin{array}{l}\text { Documentar informações importantes do projeto de } \\
\text { produto, para prover consultas futuras. Delinear a } \\
\text { produção potencializando sua reprodução. }\end{array}$ & $\begin{array}{l}\text { - Relatório do projeto } \\
\text { - Ficha técnica }\end{array}$ \\
\hline
\end{tabular}

Quadro 4 - Métodos e ferramentas da fase Desenvolver.

Fonte: Elaborado pelos autores, com base na pesquisa realizada

O conjunto dessas ações permite que o artífice aplique os conhecimentos adquiridos nas fases anteriores em uma proposta tangível de produto. Ao vivenciar tais experiências, cria uma produção direcionada a resultados mais assertivos de mercado.

\section{PESQUISA APLICADA}

Na busca por atingir a validação de seu método, o projeto Dzart promoveu (com suporte de parceiros) atuações de ensino-aprendizagem junto ao público artesão de Joinville e região, voltado para o desenvolvimento de Produtos Culturais de Artesania com Identidade Regional. Seu programa de formação, com a carga horária total de 60 horas, foi disponibilizado em 2015 e requerido pela comunidade artesã em 2016. Fundamentado em sua proposta metodológica, o projeto de pesquisa deu ênfase a estudos voltados ao contexto sociocultural da região de Joinville, interpretação e experimentação da cultura regional, viabilização da valorização cultural regional além de processos metodológicos para a concepção de produto que resultaram no desenvolvimento de produtos culturais.

O estímulo, potencializado pelo designer - ao aplicar métodos e ferramentas ponderadas ao universo do artífice - permitiu um aprender-fazendo, durante todas as fases, resultando em uma produção artesanal bastante diversificada. A Figura 5 apresenta algumas das etapas de validação da metodologia 3D's, como: aulas expositivas, aplicação de ferramentas projetuais e apresentação da proposta final. 


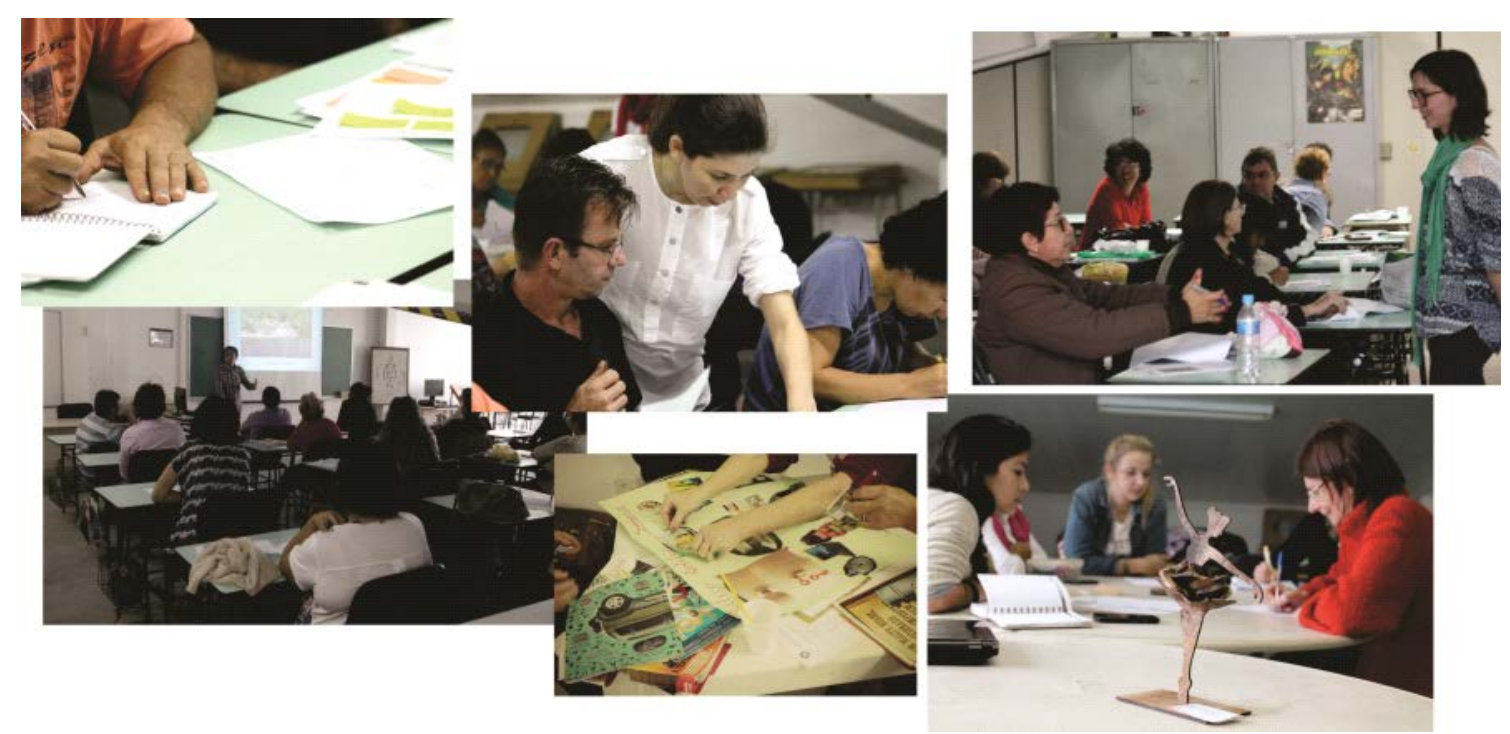

Figura 5 - Validação da Metodologia 3D`s

Fonte: Elaborado pelos autores, com base na pesquisa realizada

Durante todo o processo, o artesão foi convidado a ser protagonista do percurso necessário à concepção de produtos artesanais, enfatizando pensamentos de design. Dentre as experiências obtidas em 2015, a Figura 6 revela o grupo de artesãos envolvidos e alguns dos produtos de referencia cultural desenvolvidos com a total aplicação da metodologia 3D's.

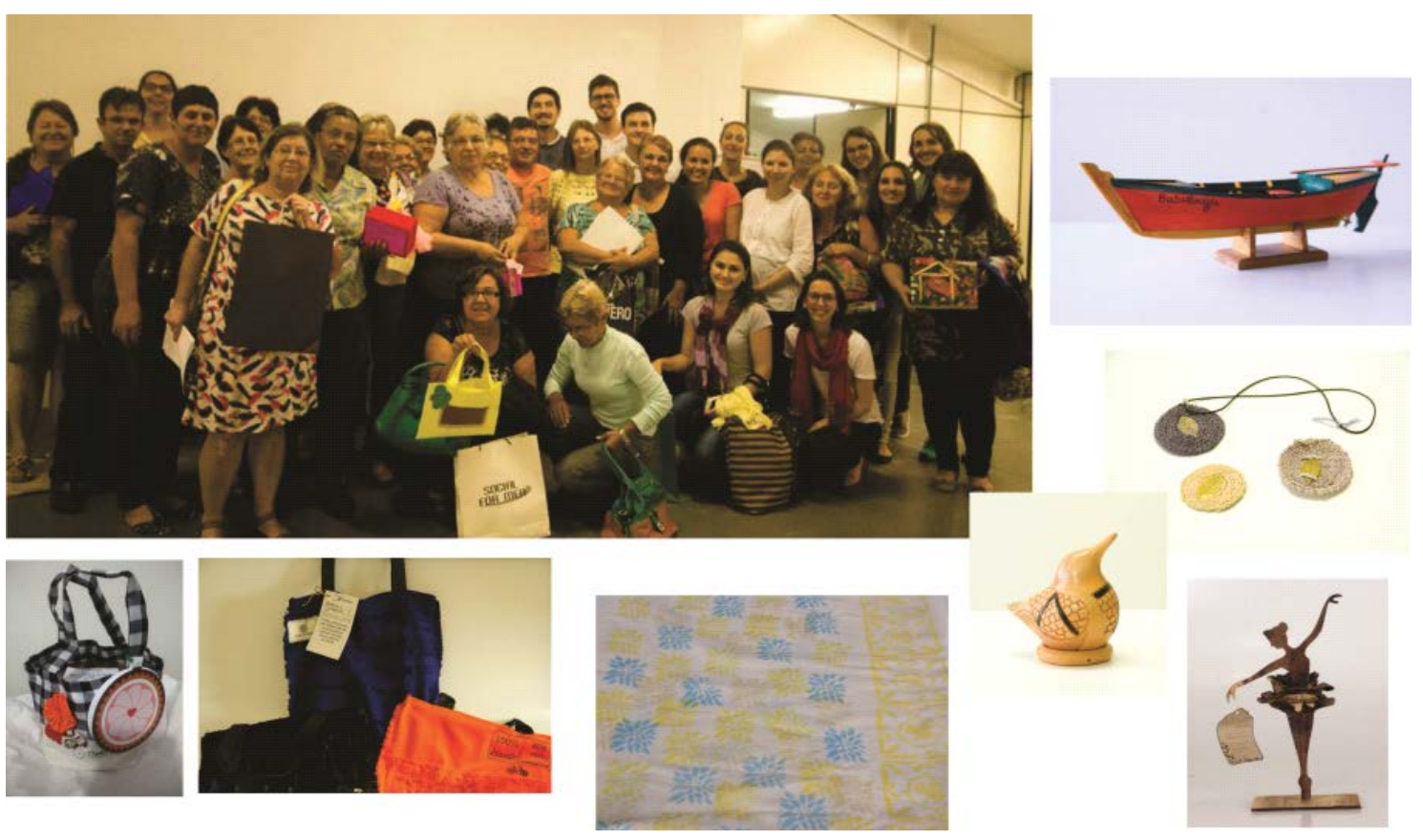

Figura 6 - Artesãos e produtos desenvolvidos com uso da Metodologia 3D`s Fonte: Elaborado pelos autores, com base na pesquisa realizada

Os produtos culturais de artesania com identidade regional, obtidos a partir da aplicação da metodologia, representam um acervo único que traduz valores e características peculiares. O percurso realizado teve o grande diferencial de resguardar a autonomia do artesão que, ao perceber seu potencial criador com a aplicação de 
uma metodologia específica, diante do resultado percebeu-se empoderado a seguir a vertente da produção autoral eliminando vestígios de copismos.

\section{CONCLUSÃO}

As relações entre design e artesania têm sido, na atualidade, amplamente discutidas, resultado de reaproximações aos fazeres originários, às habilidades e manualidades, permanentemente revisitadas pelos profissionais da área do design.

Borges (2011, p. 217) destaca a importância do artesanato como representação da identidade de um povo, reforçando que, por meio dele, "não só os materiais e as técnicas, mas também os valores coletivos são fortemente representados". E acrescenta a singularidade expressa nesses valores, cujas características únicas revelam seu idioleto "vocábulo criado no século 20 para designar a variação da língua peculiar a um indivíduo, manifestada por padrões de escolha de palavras e gramática, ou palavras, frases ou metáforas que são únicas dele" (BORGES, 2011, p. 217).

E porque, segundo essa autora, a produção artesanal é a atividade cultural de maior ocorrência nos municípios brasileiros, é importante constar que as demandas para uma proposta de abordagem metodológica com vistas à utilização em processos artesanais, fazem parte do contexto impulsionador do conteúdo ora descrito, que resultou na metodologia 3D's, cujo percurso da descoberta, decodificação e desenvolvimento são o seu fio condutor, escopo do presente artigo.

Embora tenha ancoragem nos vários estudos metodológicos da área do design, com os quais possui inúmeros pontos de contato, seu diferencial está nas experiências que congrega junto ao meio artesanal, com resultados que reforçam o mérito da sua aplicação.

A ideia de uma caixa de ferramentas para o artesão lançar mão no percurso do seu processo produtivo supõe um recurso acessível, ao alcance no decorrer de suas práticas cotidianas. Desse modo, o resultado da aplicação da metodologia 3D's pelo artesão pode ser a concepção de um novo produto ou melhoria de um existente, uma embalagem, um serviço diferenciado, sendo, portanto, inúmeras as possibilidades que podem ser viabilizadas a partir da utilização dessa proposta metodológica.

\section{REFERÊNCIAS}

BAXTER, M. Projeto de Produto: guia prático para o design de novos produtos. 2.ed. São Paulo: Edgard Blücher, 2011.

BORGES, Adélia. Design + artesanato: o caminho brasileiro. São Paulo: Editora Terceiro Nome, 2011.

BROWN, Tim. Design thinking: uma poderosa metodologia para decretar o fim das velhas ideias. Rio de Janeiro: Elsevier, 2010.

DESIGN FOR CHANGE BRASIL. Manual Design for Change. s.n.t

PINHEIRO, Tennysonet al. HumanCentered Design: Kit de ferramentas do HCD. 2.ed. s.n.t

GONSALES, Priscila. Design thinking para educadores. Instituto Educadigital, São Paulo, 2014. 
KIMBELL, L., \& JULIER, J. The Social Design Methods Menu. Londres: Fieldstudio. 2014.

LÖBACH, B. Design Industrial: Bases para a configuração dos produtos industriais. 1. ed. São Paulo: Edgard Blücher, 2001. 